\title{
Phenomenal background frequency and the concreteness/imagery effect in verbal discrimination learning
}

\author{
ELIZABETH S. GHATALA \\ Weber State College, Ogden, Utah 84408 \\ and \\ JOEL R. LEVIN \\ University of Wisconsin, Madison, Wisconsin 59706
}

\begin{abstract}
College students gave frequency ratings for concrete and abstract words which were equated on normative frequency. The results replicated the finding of Galbraith and Underwood (1973) that abstract words are perceived to be higher in frequency than concrete words. Different subjects then learned verbal discrimination lists consisting of both abstract and concrete pairs. While the usual concreteness effect was obtained when abstract and concrete items differed widely on phenomenal frequency, it disappeared when these items were equated on perceived frequency. The finding that appropriate frequency manipulations can eliminate the concreteness/imagery effect, coupled with similar findings for other stimulus characteristics, lends strong support to the frequency theory of discrimination learning.
\end{abstract}

A consistent finding reported in the verbal-learning literature is that concrete (or high-imagery) words are easier to learn than abstract (or low-imagery) words in a wide variety of tasks. including verbal discrimination learning tasks (e.g.. Paivio \& Rowe. 1970: Rowe \& Paivio. 1971b, 1972; Ullrich \& Balogh. 1972). However, a recent finding (Galbraith \& Underwood. 1973) has made the concrete-abstract difference difficult to interpret. Galbraith and Underwood demonstrated that abstract words were perceived by subjects to be higher in frequency than were concrete words even though the objective trequencies (according to the Thorndike \& Lorge, 1944. or the Kucera \& Francis, 1967, norms) of the two types of items were the same. Thus, the general experimental procedure of equating words on normative frequency when manipulating concreteness or imagery does not necessarily match the words on phenomenal background frequency. Galbraith and Underwood (1973) have suggested several explanations for this phenomenon.

One line of reasoning holds that the available norms (especially the older Thorndike-Lorge count) may not accurately reflect the experienced word

This research was funded by the Wisconsin Research and Development Center for Cognitive Learning, supported in part as a research and development center by funds from the National Institute of Education, and no official endorsement by the National Institute should be inferred. Center No. NE-C-00-3-0065. We are grateful to Judy Van De Graff for collecting the data in Experiment II and to Marion Bushell for typing the paper. Requests for reprints should be addressed to Elizabeth S. Ghatala, Psychology Department, Weber State College, Ogden, Utah 84408. frequency of current college students. That is, it is possible that present day college students may have been exposed far more frequently to abstract words as compared to concrete words than is reflected in the norms. However, another possibility raised by Galbraith and Underwood is that subjects overestimate the frequency of abstract words because of a correlated property (e.g., contextual variety) of abstract words. In this paper. the term "phenomenal background frequency" refers only to the operations used to obtain this frequency measure and is neutral with respect to why abstract and concrete words differ on it when equated on available objective measures of frequency.

The confounding of phenomenal frequency with the concreteness variable is especially serious in the case of the verbal discrimination task, since the tenets of the major theory of verbal discrimination learning (Ekstrand, Wallace. \& Underwood, 1966) lead to the prediction that preexperimental frequency of items should be inversely related to ease of learning in this task. Moreover, this prediction (given proper controls) has been upheld in our own recent experiments (Ghatala, Levin, \& Makoid, 1975, Experiments 1 and 2). Therefore, it is quite conceivable that the concreteness (imagery) effect in verbal discrimination tasks may be due to preexisting frequency differences rather than to differences in concreteness or imagery per se. The experiments reported here address this problem.

In the first experiment, we obtained phenomenal frequency values for abstract and concrete words which were also widely separated on imagery but 


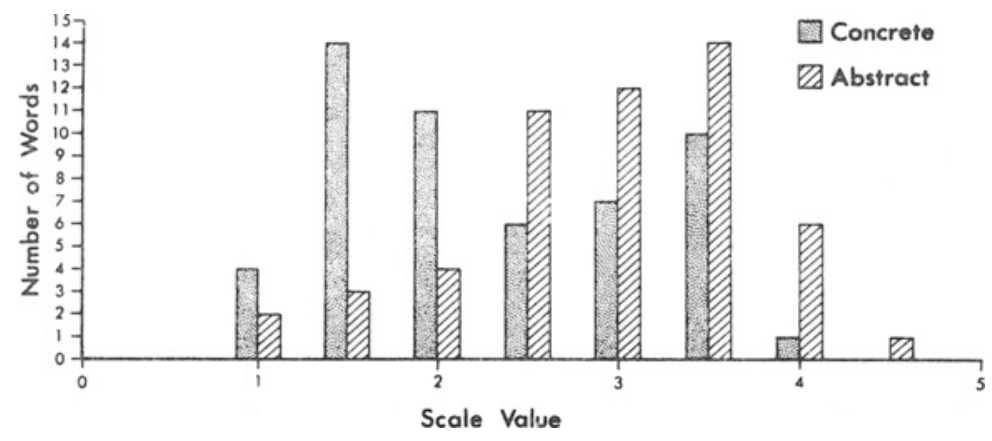

\author{
Figure 1. Number of concrete and abstract \\ words asaigned to each half-step value on the \\ backgroand frequency seale.
}

which were matched on Thorndike-Lorge frequency and meaningfulness. In this regard, no systematic attempt was made by Galbraith and Underwood to ensure that their concrete and abstract words were also separated on imagery. However, since these dimensions are highly correlated, it is reasonable to assume that their stimuli differed in imagery as well as concreteness (cf. Paivio. Yuille, \& Madigan, 1968). Neither did Galbraith and Underwood equate their concrete and abstract words on meaningfulness. As will be shown, however, even with our added control of item attributes, the abstract (low-imagery) words were rated higher in perceived frequency on the average than were the concrete (high-imagery) words-thereby replicating Galbraith and Underwood. The ratings obtained in Experiment I were then used in Experiment II to separate the effects of phenomenal frequency and concreteness/ imagery in verbal discrimination learning.

\section{EXPERIMENT I}

\section{Method \\ Subjects. The subjects were 40 college students enrolled in an introductory psychology course at Weber State College. \\ Materials. Fifty-three concrete and 53 abstract nouns were selected from the Paivio et al. (1968) norms. The average concreteness rating for the concrete words was 6.72 , with a range of 5.75 to 7.00 . The abstract words averaged 2.55 on the 7 -point concreteness scale, with a range of 1.48 to 3.73 . The two item types were also widely separated on the imagery attribute: Mean imagery rating for the concrete words was 6.27 , with a range of 5.63 to 6.77 ; mean imagery value for the abstract words was 3.32 , with a range of 2.13 to 4.00 . \\ To achieve equal Thorndike-Lorge frequencies for the two sets of words. pairs of abstract and concrete words were selected so that the words in each pair were equal or very near equal in frequency. In order to obtain a large number of such matched pairs, a wide range of frequency levels had to be sampled. Thus, the concrete words ranged from 1 to 199 occurrences per million, with an average of 36.83 . The frequencies of the abstract words ranged from 1 to 201 occurrences per million, with an average of 36.46 . Finally, the average meaningfulness value for the concrete words was 5.87 , with a range of 4.75 to 6.44 . For the abstract words, the average meaningfulness value was 5.65 , with a range of 4.92 to 6.60.}

Procedure. The 106 words were randomly ordered in a two-page booklet. three columns per page. Each student in the class individually rated the words for background frequency along a 5-point scale. To the tight of each word was a short line for the subject to record a number indicating his judgment of frequency. The instructions read by the experimenter informed the subjects that words differed widely in their frequency of use in printed and oral discourse and that their task was to rate each word on the 5-point scale according to how frequently they thought they encountered the word. The cover sheet contained verbal descriptions of the 5 points of the frequency scale as follows: 1 , hardly ever encounter the word; 2, sometimes but not often; 3 , medium often; 4 , fairly often; 5 , very often. The numbers and descriptions also appeared at the top of both pages containing the words. The four anchor words used by Galbraith and Underwood (1973) were given on the cover sheet along with scale values: water-5. figment-1, belfry-1, throught -5 . Subjects were instructed that the words varied in frequency and that they were to use all 5 points on the scale, but there was no requirement to use each point equally often. Half of the subjects received the words in one randomly determined order, while the other half received the reverse of this order. The test was unpaced.

\section{Results and Discussion}

The average of the scale values assigned by the $\mathbf{4 0}$ subjects was calculated for each of the 106 items. After Galbraith and Underwood (1973), these mean values were grouped according to $1 / 2$-unit scale steps, and the number of abstract and concrete items in each group were counted. Figure 1 shows that the distributions of abstract and concrete items over the scale are quite different. The overall mean value for the 53 abstract words was $3.18(S D=.78)$, and for the concrete words, $2.54(\mathrm{SD}=.88)$. When analyzed across subjects, these mean values differed significantly, $F(1,39)=117.42, p<.001$. Of the 40 subjects, only 2 gave a higher mean to the concrete than to the abstract words.

These results are in complete accord with those obtained by Galbraith and Underwood (1973, Experiment 3). At the same time, our findings extend those of Galbraith and Underwood, since the present samples of abstract and concrete words were also systematically separated on imagery and equated on meaningfulness.

Thus-for whatever reason-abstract (lowimagery) words are perceived by subjects to be higher in background frequency than concrete (highimagery) words, even though the two sets of words are of equal frequency in the Thorndike and Lorge tables. Since, as mentioned earlier, there is evidence 
that background frequency is an important variable in verbal discrimination learning, an obvious hypothesis is that this variable is responsible for the concreteness/imagery effect found in the task. Experiment II provides a straightforward test of this hypothesis.

\section{EXPERIMENT II}

The design of the present experiment is similar to that employed by Levin, Ghatala, and Wilder (1974) to explore apparent frequency differences between pictures and words. The logic is quite simple. If phenomenai background frequency underlies the concreteness/imagery effect in verbal discrimination learning, then equating concrete (high-imagery) words and abstract (low-imagery) words on phenomenal frequency should eliminate (or at least reduce) the usual difference favoring the former type of items. In contrast, when abstract and concrete words are allowed to vary on phenomenal frequency, the usual concreteness/imagery effect should be obtained.

\section{Method}

Materials. Using the mean scale values obtained in Experiment 1. we were able to select 18 concrete and 18 abstract words which were nearly equal on phenomenal frequency. The characteristics of these items. labeled "small-difference items." are given in the upper portion of Table 1 . Note that the phenomenal frequency means and ranges were virtually identical for these abstract and concrete words. Moreover. the Thorndike-Lorge frequency and meaningfulness values of these small-difference abstract and concrete items were closely matched. The only variables on which the items differed were concreteness and imagery. Within the small-difference item set, the abstract words were paired consecutively on the basis of the phenomenal frequency ratings (so) as to make intrapair phenomenal frequencies as close as possible). Nine concrete pairs were also created in this fashion. The 9 abstract and 9 concrete pairs were put together to form an 18-pair verbal discrimination list which constituted the small-difference condition. so labeled because of the small difference in phenomenal frequeniy between the abstract and concrete pairs in the list. The words within each pair were typed side by side on $5 \times 8$ in. cards, which were then fastened into a ringed binder.

Following the formation of the small-difference list. we selected a different set of 18 concrete and 18 abstract words which were labeled "large-difference items." As can be seen in the bottom part of Table 1. the abstract words in the large-difference item set had considerably higher phenomenal frequencies than did the concrete words in this set. The Thorndike-Lorge frequencies and meaningfulness values for the large-difference concrete and abstract words were closely matched. Thus, the large-difference items varied on concreteness and imagery and on phenomenal background frequency. A mixed list consisting of nine abstract and nine concrete pairs was formed from the large-difference items in the same manner as for the small-difference items. This list constituted the large-difference (in phenomenal frequency) condition of the experiment.

Three presentation orders of each list were constructed such that: (a) within each order, the occurrence of abstract and concrete pairs was random; (b) within an order, the correct items were located on the right for half the pairs and on the left for the other half; (c) for a random half of the pairs. the spatial location of the correct item changed between orders: and (d) for all pairs, the spatial location of
Table 1

Characteristics of Abstract and Concrete Items in Experiment II

\begin{tabular}{lrccc}
\hline & \multicolumn{2}{c}{ Abstract } & \multicolumn{2}{c}{ Concrete } \\
& Mean & Range & Mean & Range \\
\hline & \multicolumn{4}{c}{ Small-Difference Items } \\
PBF & 2.79 & $1.30-3.95$ & 2.79 & $1.32-3.95$ \\
TLF & 21.83 & $1-74$ & 21.39 & $1-60$ \\
I & 3.34 & $2.77-3.83$ & 6.24 & $5.63-6.77$ \\
C & 2.50 & $1.52-3.72$ & 6.70 & $5.75-6.96$ \\
m & 5.56 & $4.92-6.60$ & 5.71 & $4.75-6.44$ \\
& \multicolumn{4}{c}{ Large-Difference Items } \\
PBF & 3.37 & $2.72-4.37$ & 1.81 & $1.34-2.35$ \\
TLF & 20.44 & $1-80$ & 20.27 & $1-86$ \\
I & 3.25 & $2.47-4.00$ & 5.25 & $5.97-6.60$ \\
C & 2.69 & $1.79-3.73$ & 6.71 & $5.96-7.00$ \\
m & 5.67 & $5.25-6.12$ & 5.88 & $5.32-6.44$ \\
\hline
\end{tabular}

Note-PBF = phenomenal background frequency; $T L F=$ Thorndike-Lorge frequency, $I=$ imagery, $C=$ concreteness, $m=$ meaningfulness.

the correct item changed at least once across the three orders. One item in each pair was randomly chosen to be correct. Half the subjects in each condition received a second version of the list in which the other member of each pair was correct.

Procedure. Each subject was tested individually. The subject was seated beside the experimenter, who presented the pairs in the list by turning cards in the appropriate notebook. Each pair was shown for $3 \mathrm{sec}$ (timed by a stopwatch), and then the same pair was shown immediately again with the correct member indicated by a plus sign drawn beneath it. Each subject received one study trial, during which he did not respond. The experimenter pronounced both words in each pair on the anticipation phase of the study trial. Four anticipation test trials followed the study trial. Because five trials were given, two of the three orders were repeated within a session. The intertrial interval was $5 \mathrm{sec}$. Conventional verbal discrimination instructions for the anticipation procedure were given.

Subjects. College students in introductory psychology classes at Weber State College participated in the experiment. Twenty-six subjects were assigned randomly to the large-difference and small-difference conditions for a total of 52 subjects. The decision concerning sample size was based on a pilot study in which subjects from the present population learned a mixed list of concrete (highimagery) and abstract (low-imagery) pairs selected without regard to phenomenal frequency. Following Walster and Cleary's (1970) simultaneous procedure. the pilot results suggested that if separate abstract-concrete comparisons were to be performed within largeand small-difference lists. 26 subjects per list would be appropriate in order to have adequate statistical power to detect an "important" difference (though not enough to detect a "trivial" difference), when each test is performed using $a=.0$ i.

\section{Results}

The mean numbers of correct responses over four trials were calculated for the nine abstract and nine concrete pairs for each condition. List version was included as a factor in the analysis, but in neither the small-difference nor the large-difference condition did it emerge as a significant main effect or in interaction with concreteness (all ps $>.05$ ). Within the large-difference condition, the mean correct (out of a possible 36) for the abstract pairs was 27.46 ( $\mathrm{SD}=$ 4.37). The corresponding mean for the concrete pairs was $30.50(\mathrm{SD}=4.36)$. As expected, this difference 
was significant using $a=.01, F(1,24)=23.71$, $\mathrm{p}<.001$. On the other hand, performance on the two types of pairs within the small-difference condition showed a different pattern: abstract, $\bar{X}=29.58$ (SD $=4.15)$; concrete, $\bar{X}=30.23(S D=4.52)$; with the test of the difference at $a=.01$ being nonsignificant, $\mathrm{F}(1.24)=1.03, \mathrm{p}>.25$. In both conditions, performance improved significantly with trials (both ps $<.01$ ); however. for neither condition did this interact with the abstract-concrete variable (both Fs $<1$ ).

\section{Discussion}

The results are ciear-cut. When items differing in concreteness and imagery are equated on phenomenal background frequency, the concreteness/imagery effect in verbal discrimination learning disappears. However, the usual effect of concreteness/imagery is found when abstract items are allowed to have higher phenomenal frequency than concrete items. According to the results obtained in Experiment I, this latter state of affairs has probably occurred naturally in verbal discrimination experiments where the concreteness and imagery attributes of words have been manipulated while objective frequency has been controlled.

This notion is supported by the finding that ratings obtained in Experiment $I$ on the words utilized in the pilot study - the ratings were obtained after the pilot study was conducted-indicate that differences in phenomenal frequency can be substantial under the usual circumstances in which abstract and concrete words are compared (i.e., when they are equated in terms of normative frequency and meaningfulness). Thus, the average phenomenal frequency value for the concrete words in the pilot study was 2.86 , with a range of 1.60 to 4.27 . The average value for the abstract words was 3.46 , with a range of 2.40 to 4.37 . The procedure utilized in the pilot study was virtually identical to that of Experiment II. The mean number of correct responses in four trials for the concrete pairs was $27.00(S D=3.43)$, that for the abstract pairs was $24.60(\mathrm{SD}=4.33)$. With 20 subjects, the difference was significant, $F(1,19)=16.78, p<.001$.

When the pilot data are considered along with the large- and small-difference conditions in Experiment II, it becomes apparent that the magnitude of the difference in mean performance on concrete and abstract pairs increases as the phenomenal frequency difference between them becomes larger. Thus, the standardized mean difference between abstract and concrete pairs on total correct responses in the small-difference condition was.20. In the pilot study, the standardized mean difference (associated with a moderate phenomenal frequency difference) between abstract and concrete pairs was .71. Finally, in the large-difference condition, the standardized mean difference was .93 .

The results reported thus far provide indirect evidence that phenomenal background frequency influences verbal discrimination learning. However, a direct test of the effect of this variable was made by comparing pairs low in phenomenal frequency (mean rating $=1.99$ ) with pairs high in frequency (mean rating $=3.60$ ) within the small-difference list. Abstract and concrete item types were equally represented at the two levels of frequency. Performance on the eight low-frequency pairs over four trials $(\overline{\mathrm{X}}=27.35$; $\mathrm{SD}=3.61$ ) was significantly better than performance on the eight high-frequency pairs $(\bar{X}=25.50 ; S D=4.19), F(1,25)=13.40$, $\mathrm{p}<.001$. On the basis of these findings, we conclude that verbal discrimination learning is influenced by phenomenal frequency and that differences between abstract and concrete words on phenomenal background frequency underlie the concreteness/ imagery effect in verbal discrimination learning.

We have elaborated elsewhere (Ghatala \& Levin, 1974; Ghatala et al., 1975; Ghatala, Levin, \& Wilder, $1975)$ the mechanism by which background frequency is believed to influence verbal discrimination learning. Briefly, the logic is that situational frequency inputs combine with preexperimental (background) frequency in a manner akin to Weber's law. Thus, situational frequency inputs to items low in background frequency should be more discriminable than inputs to items high in background frequency, and, in fact, they are (Ghatala \& Levin, 1974; Ghatala et al., 1975).

According to theory (Ekstrand et al., 1966) and empirical evidence (Ghatala, Levin, \& Subkoviak, 1975; Underwood \& Freund, 1970), frequency discriminations are the basis for performance in the verbal discrimination task under normal circumstances. Therefore, the greater the discriminability of situational frequency, the better the learning.

In conclusion, this study provides strong support for the notion that phenomenal background frequency is an important variable in verbal discrimination learning. Moreover, the effects obtained when attributes such as concreteness and imagery are manipulated can be accounted for in terms of their covariation with phenomenal frequency-just as picture-word differences in discrimination learning (e.g., Rowe \& Paivio, 1971a) are traceable to corresponding differences in apparent frequency (see Levin et al., 1974). And, since the effects ostensibly due to these stimulus characteristics can be reliably made to vanish under controlled frequency manipulations, the case for Ekstrand et al.'s (1966) theory of discrimination learning emerges stronger than is currently portrayed even by 
its presumed proponents (cf. Eckert \& Kanak, 1974 Wallace. 1972).

\section{REFERENCES}

ECKERT, E.. \& KANAK, N. J. Verbal discrimination learning: A review of the acquisition, transfer, and retention literature through 1972. Psychological Bulletin, 1974, 81, 582-607.

Ekstrand, B. R.. Wallace, W. P., \& Underwood. B. J. A frequency theory of verbal discrimination learning. Psychological Review, 1966, 73, 566-578.

Galbraith, R. C.. \& Underwood. B. J. Perceived trequency of concrete and abstract words. Memory \& Cognition. 1973, 1. $55-60$.

Ghatala. E. S., \& Levin, J. R. Discrimination learning as a function of differences in materials: A proposed explanation. Memon \& Cognition, 1974, 2, 395-400.

Ghatala, E. S. Levin, J. R.. \& Makoid, L. A. A claritication of frequency effects in children's discrimination learning. Memon \& Cognition. 1975, 3.1.6.

Ghatala, E. S.. Levin. J. R., \& Subroviak, M. J. Rehearsal strategy effects in children's discrimination learning: Confronting the crucible. Journal of Verbal Leaming and Verbal Behavior. 1975, 14, 398-407.

Ghatala, E. S., Levin, J. R.. \& Wilder. L. Pronunciation and the frequency-meaningfulness effect in children's frequency discrimination. Journal of Experimental Psychology: Human Learning and Memory, 1975. 1. 655-659.

KuĆERA. H.. \& Francis, W. N. Computational analyses of present-day American English. Providence: Brown University Press. 1967.

Levin. J. R.. Ghatala, E. S., \& Wilder, L. Picture-hord differences in discrimination learning: I. Apparent frequency manipulations. Joumal of Experimental Psychology. 1974 102. $691-695$
Parvio. A.. \& Rowe, E. J. Noun imagery, trequency and meaningfulness in verbal discrimination. Journal of Experimental Psychology, 1970. 85, 264-269.

Paivio. A., Yuille, J. C.. \& Madigan, S. Concreteness, imagery. and meaningfulness values for 925 nouns. Journal of Experimental Psychology. 1968. 76(1, Pt. 2).

Rowe. E. J.. \& PaIvio. A. Discrimination learning of pictures and words. Psychonomic Science, 1971, 22, 87.88. (a)

Rowe. E. J.. \& Paivio, A. Word frequency and imagery effects in verbal discrimination learning. Journal of Experimental Psychology, 1971, 88. 319.326. (b)

Rowe. E. J.. \& PaIvio. A. Effects of noun imagery, pronunciation, method of presentation, and intrapair order of items in verba discrimination. Joumal of Experimental Psychology, 1972, 93, 427.429 .

ThORNDIKE, E. L.. \& LORGE, I. The teacher's word bonk of 30,000 words. New York: Bureau of Publications. Teachers College. Columbia University, 1944

UlLRICH, J. R., \& BALOGH, B. A. Imagery and meaningfulness of right and wrong items in verbal discrimination learning. Psychonomic Science, 1972, 29, 68-70.

UNDERWOOD, B. J., \& Freund, J. S. Relative frequency judgments and verbal discrimination learning. Journal of Experimental Psychology, 1970, 83, 279-285.

WALlace, W. P. Verbal discrimination. In C. P. Duncan \& L. B. Sechrest (Eds.), Human memory: Festschrift for Benton J. Underwood. New York: Appleton-Century-Crofts. 1972.

Walster, G. W., \& Cleary, T. A. Statistical signiticance as a decision-making rule. In E. F. Borgatta \& G. W Bohrnstedt (Eds.). Sociological methodology. San Francisco: Jossey-Bass. 1970.

(Received for publication July 7,1975 revision received September 12, 1975.) 